\title{
Case Study Research, Philosophical Position and Theory Building: A Methodological Discussion
}

Thakur Prasad Bhatta

\begin{abstract}
Case study research though increasingly popular in social sciences for positivist and intrepretivist research, a kind of confusion is prevalent when it is used ignoring its philosophical position. Arguably, the case study research is considered more appropriate for qualitative research because of its foremost strength - the in-depth study of complex issues. This paper, drawing from the literature, discusses the philosophical position of case study research and argues that qualitative case study research is appropriate for theory building. For theory building, this paper follows the inductive approach guided by qualitative research paradigm and argues that it is not appropriate to assess theory building from the perspective of quantitative research. Very similar to other research methods, it is natural that the case study research has certain challenges; however, most of the challenges and misunderstandings overlap causing difficulty to understand the role of case study research. Hence, this paper aims to contribute to the understandings of the challenges and misunderstandings associated with the theory building from case study research. This paper argues that most of the challenges associated with theory building from case study can be addressed employing appropriate research strategies particularly clear understanding of philosophical stance and selection of appropriate case. The misunderstandings, on the other hand, are arisen due to the differences in the researcher's perspectives particularly positivistic thinking of them rather than the shortcomings inherent in the qualitative case study research design.
\end{abstract}

Key words: case study research, philosophical position, quantitative, qualitative, theory building

\section{Introduction}

Case study research is increasingly popular as it has been widely used in multiple disciplines (Bartlett \& Vavrus, 2017) with its extensive use in social sciences (Crowe, Cresswell, Robertson, Huby, Avery \& Sheikh, 2011; Johansson, 2003). Particularly it has gained its credibility as a research methodology in exploring complex phenomenon based on the real context (Harrison, Birks, Franklin, \& Mills, 2017). However, case study research has gone through conflicting reality as it is on one hand practiced widely but on the other it is also looked sceptically among influential academicians (Flyvbjerg, 2011). Indeed, it has gone through different phases with mix of high and low recognition in different time periods (Harrison, Birks, Franklin, \& Mills, 2017). In spite of its wider use, case study research has been facing certain challenges in the research field particularly in understanding and perceiving its research outcomes. One of the main problems is to be influenced highly by the statistical methods and perceive the case study research in light of the assumptions made for statistical methods (George \& Bennett, 2004). Such tendency has undermined the methodological strength of case study for in-depth study of a particular phenomenon.

Thus, there are still problems in recognising the role of case study research in academic field as it has been " the subject of critique and confusion" (Rule \& John, 2015, p.1). It is natural that like other research methods, the case study research has certain challenges; however, surprisingly there are more misunderstandings associated with it (Flyvbjerg, 2011; Gummesson, 2014) than the challenges. Further, most of the challenges and misunderstandings overlap causing the overall understanding of the case study research somewhat messy for novice researchers. This state of confusion has led to lesser recognition of the roles of case study research limiting it as a complementary research activity than as an independent research approach. Undermining the philosophical position of case study research has played a role in creating such confusion among the researchers.

Such confusion has constrained the understanding of the roles of case study in social science research. An important instance of it is the lesser recognition of case study research in theory building. This all suggests for clear philosophical understandings of various ontological assumptions of the case study research. Hence, in this paper at first I attempt to make clear the philosophical position of case study research. Moreover, I proceed to discuss the role of case study research in theory building. Iargue that the role of case study research in theory building has been undermined due to the influence of positivist paradigms and trend of perceiving the qualitative nature of case study research from the assumptions of quantitative approaches. My aim in this paper is to contribute to the understanding of the philosophical positions of case study research and explaining its role in theory building. 
My arguments constructed in this paper are based on the discussion of literature of case study research. In this paper, I deal with methodological aspect of the case study research with particular focus on theory building. For the purpose of this paper I have used the term interpretivist and constructivist interchangeably since there is no significant difference between these two paradigms as both are guided by the same ontology of multiple realities under the broader umbrella of qualitative research. Similarly, I have used the term positivist and quantitative interchangeably to denote the quantitative research approach. It is necessary to make clear that among two traditions of case study research positivist and non-positivist, this paper deal with only the latter specifically the qualitative case study research. I have discussed these two traditions of research in the next section.

I have organized this paper into four sections including this first introduction section. The second section that follows this introduction provides background for this paper that discusses the philosophical position of case study research. Within this section I also discuss the definitional issue of the case study and types of case study that provides background in understanding case study research. In the third section, I discuss the roles of case study research in theory building and the challenges and misunderstandings associated with it. Finally, in the fourth conclusion section, I conclude the paper drawing from the overall discussions made in the paper.

\section{Philosophical Position of Case Study Research}

There are different research paradigms in practice in social science research. Mainly two broad research paradigms quantitative and qualitative hold social research in practice. Among the social science researchers some advocate quantitative research and some believe in qualitative research (Mills, Eurepos, \&Wiebe, 2010). Meanwhile, there is also another group of social researchers who argue for the possible combination of these two different approaches for better understanding of a phenomenon (Atieno, 2009; Creswell, 2003). However, the concept of mixed method is contradictory as the quantitative and qualitative research paradigms hold different ontological assumptions (Atieno, 2009). Quantitative or positivist perspective believes on independent single reality while qualitative or interpretive perspective holds assumption of contextual multiple realities (Harrison, Birks, Franklin \& Mills, 2017). This suggests that philosophical assumptions shape the nature of any research including the case study research.

Since philosophical position determines the ontological and epistemological characteristics of a research, it becomes fundamental for a research design. In this sense philosophical position of case study research is not clear as both positivist and non-positivist researchers use case study. Various theoretical streams inform case study research (Chadderton\& Torrance, 2012) that are associated with both quantitative and qualitative research tradition. Thus, the philosophical position of case study research itself has been a challenge as both the positivists and interpretivists employ it. Because of this philosophical duality, though case study is popular in research practice, there are also differences in understanding it. As a result we can find different perspectives of case study propounded by various authors. They are termed in various ways such as constructivist, methodologist, pragmatist, educationist (Baxter \& Jack, 2008; Brown, 2008; Simons, 2009; Harrison, Birks, Franklin \& Mills, 2017; Yazan, 2015). However, primarily there are two fundamental philosophical orientations that influence research endeavors - positivism or quantitative methodology and non- positivism known as constructivist and interpretivist paradigms (Harrison, Birks, Franklin, \& Mills, 2017). It is essential to distinguish these two philosophical positions while discussing the various approaches of case study research.

Nevertheless, there is prevalent tendency of ignoring the philosophical position of case study research while using its different approaches (Boblin, Ireland, Kirkpatrick \&Robertson, 2013). This has been problematic in understanding and interpreting the various approaches of the case study research. For example, Baxter and Jack (2008) consider the approaches of case study of both Stake and Yin guided by constructivist paradigm. However, Harrison, Birks, Franklin \& Mills (2017) see Yin as positivist and Stake as constructivist. It is not convincing to consider Yin as constructivist as he appears more mechanistic in his approach with the suggestions of linear procedural steps of case study research (Yin, 2014). Yazan (2015) considers Yin as positivist when he comments that though Yin does not make his epistemological position clear in explaining case study research his views on case study design and implementing approaches how his inclination towards positivism. Similarly, Brown (2008) also labels Yin as a methodologist.

Since the structured methodology of case study as postulated by Yin limits the innovation and flexibility in research, he cannot be considered constructivist. Constructivism allows flexible process to have interactions between researcher and research participants. Yet it is difficult to pronounce Yin as fully positivist. Since he talks about both the use of theory in pre-research stage and theory generation from case study research (Yin, 2014) it appears that he has taken case study as a research approach which combines certain aspects of both qualitative and quantitative traditions. Further, Yin's concept of "analytic generalisation" (2014, p. 40) suggests that his approach also draws upon qualitative research. Though there are some notions of interpretive research in his case study approach, philosophically Yin follows post-positivist tradition of research.

Unlike Yin, Stake is explicitly constructivist in his epistemological understanding on his case study approach (Yazan, 2015) as his approach is "underpinned by a strong motivation for discovering meaning and understanding of experiences in context" (Harrison, Birks, Franklin \& Mills, 2017, para, 25). Like Yin and Stake another researcher that is discussed in the field of case study research is Merriam. 
Merriam's approach is considered constructivist as she views that qualitative case study is informed through the epistemology of constructivism" (Yazan, 2015. Some researchers have labelled her as pragmatic constructivist as she suggests researchers to follow processes in analyzing, interpreting and reporting case study data (Harrison, Birks, Franklin \& Mills, 2017). Thus the approaches of these three prominent writers of case study research are different in the philosophical sense. According to Brown (2008), Yin as a methodologist and Stake as constructivist, can be put in two different ends of a continuum while Merriam lies in the middle of it.

Thus, there are both positivist and constructivist approaches of case study research. However, use of case study research and its relevancy for qualitative study is more prominent as the notion of qualitative research is to study complex social phenomenon which is not appropriate to do with the quantitative approach of research. Gummesson (2014) argues that quantitative research approach is suitable only to study simple phenomenon but it is essential to employ qualitative approach to explore complex phenomenon. This clearly suggests the differences of purpose of case study research in qualitative and quantitative research approach. Further, it is viewed that because of its nature of mainly studying complex issue in details (Crowe, Cresswell, Robertson, Huby, Avery \& Sheikh, 2011), case study is more used for qualitative research (Gummesson, 2007). More importantly it is believed that "qualitative paradigms are broad and can encompass exploratory, explanatory, interpretive, or descriptive aims" (Harrison, Birks, Franklin, \& Mills, 2017, para 18).

Furthermore, most important strength of case study research is that it responds how and why type research questions (Baxter and Jack, 2008) which are relevant to qualitative research. By posing the how and why questions the case study research intends to conduct an intensive study for deeper understanding of particular theme, programme, policy, organization, event and activity occurring in society (Simons, 2009). Within the qualitative research, a special feature of case study research is that it focuses to the depth of any social issue (Baskarada, 2014) than its breadth. It needs to be noted here that the depth over breadth of a phenomenon is the concern of the case study research for which qualitative research is an appropriate approach.

The discussions above suggests that the researcher needs to be clear on the objective of study while undertaking a case study research that helps researcher to take appropriate philosophical position - positivist or interpretive. Only with the clarity in the philosophical position it becomes possible to address the challenges and misunderstandings associated with any research approach. With the mix up of the philosophical positions it becomes difficult to address the issues of any research due to the contradictory beliefs of the different research paradigms- quantitative and qualitative. Based on the above discussion, I align myself to the qualitative case study research and this paper is informed by the qualitative or interpretive research paradigm. Further, discussions on theory building in this paper are based on the qualitative case study research and follow the inductive reasoning instead of deductive reasoning of quantitative approach (Rule \& John, 2015).

\section{Defining Case Study and its Types}

With the above discussion on philosophical position of case study research it is imperative to discuss the definitional issue of case study and its types as it provides background for further discussion of theory building in this paper. One of the theoretical problems of case study research lies in its definition as it has been defined in various ways by its authors (Harrison, Birks, Franklin \& Mills, 2017; Yazan, 2015). I believe that discussions on the various definitions help researchers to understand the features of case study research. Yin, a prominent author of case study research, admits that it is very difficult to define the term case study (Yin, 2014). Yet he tries to define it in terms of an in-depth research of a phenomenon intertwined with the particular context using various sources of data. Flyvbjerg (2011) also emphasizes detail in depth study as he views that "The main strength of the case study is depth- detail, richness, completeness, and within-case variance" (p. 314). According to Dooley (2002) case study research is to develop understanding of multifaceted phenomenon. However, Stake (1994) opines that a case under case study research is not only complex study as it also takes simple case for the research. Gerring ( 2007) defines case study "as the intensive study of a single case where the purpose of that study is - at least in part - to shed light on a larger class of cases (a population)" (p. 20). But, this definition limits case study in the study of single case while there can be both single and multiple cases depending upon the purpose of the research (Yin, 2014).

Thus it appears that case study is defined in various ways. However, there are also common characteristics among the various definitions though not fully unanimous definition. The most common feature of case study is intensive study of a phenomenon which means the procedure of going into depth than the breadth of any phenomenon. These definitions also suggest that when the case is complex it requires in-depth study and for which qualitative case study research is useful for holistic understanding of the phenomenon. Considering all these aspects of case study, definition put forward by Simon (2009) appears relatively comprehensive as she defines case study as "an in-depth exploration from multiple perspectives of the complexity and uniqueness of a particular project, policy, institutions, programme or system in a 'real life' context' (p. 21). This paper perceives case study close to this definition.

After the definitional discussions, it is imperative to review briefly the various kinds of case study as they are used for different purposes of research. Thomas (2011) has mentioned three kinds of case studies- key case, outlier case and local knowledge case - one can take depending upon the focus of the research. For example, according to Thomas, if one's focus is to present an exemplary story of a phenomenon the key case is appropriate. Yin (2014) 
identifies case study as explanatory, exploratory, and descriptive. In view of theory building, explanatory and exploratory designs are useful while descriptive is useful for understanding of case or cases. Stake (1994) categories case study into intrinsic, instrumental and collective. When focus of research is the case intrinsic design is used while instrumental design is used when focus of research is the issue rather than case (Yazan, 2015; Baxter \& Jack, 2008). So, intrinsic is used to get better understanding of a particular case while instrumental and collective case studies are used to develop theory (Berg, 2007). Collective case study is simply the expanded form of instrumental case study as it has multiple cases for study instead of single case which is useful to have "better understanding" and "better theorizing" (Stake, 1994, p. 237) from them.

Thus, the various kinds of case study postulated by different authors have their distinct meanings as well as some similarities. But, I found the Stake's classification more useful. From his classification I see that instrumental case study is appropriate for theory building as it provides "insight into an issue" (Stake, 1994, p. 237) which helps in drawing theoretical generalisation. As Merriam (2009) quotes Stake the instrumental case study "is examined mainly to provide insight into an issue or to redraw a generalisation" (p. 48). According to Berg (2007), instrumental case study intends to develop theoretical understanding of a phenomenon. Further, Stake (1994) views that the purpose of intrinsic case study is to understand a particular case not to draw generalisation and theory building while in the instrumental case study "a particular case is examined to provide insight into an issue or refinement of theory" (p. 234). Hence, for the purpose of theory building choosing the right type of case is essential. For this the concept of theoretical sampling is used in qualitative research instead of representative sampling as in quantitative research.

\section{Theory Building from Case Study Research}

Conceptually, theory and theory building are intertwined terms but carry different meanings in the process of research. Theory, according to Strauss and Corbin (1998), "denotes a set of well developed categories (e.g. themes, concepts) that are systematically interrelated through statements of relationship to form a theoretical framework that explains phenomenon" (p. 22). Meanwhile theory building is defined as the "ongoing process of producing, confirming, applying, and adapting theory" (Lynham, 2000; as cited in Lynham, 2002, p. 222). In this sense we can say that theory is the product while theory building is a process that takes extended time to be developed into a theory. Swedberg (2012) rightly explains that "While theorizing is primarily a process, theory is the end product" (p. 1). Thus, theory building in general is an iterative and complex process. Theory building, according to Thomas (2011), is "about developing, almost from scratch, a framework of ideas, a model that somehow explains the subject you are researching" (p. 112). Some authors consider theory building as a creative work
(Shoemaker,Tankard, \&Lasorsa, 2004) which suggests use of qualitative approach that allows iterative and flexible process instead of structured and straightforward process of quantitative approach.

Case study has been used both for theory testing and theory building. The former is mainly associated with the quantitative research while the latter relates to the qualitative research. But, arguably, case study is considered important research method for theory building. It is because one of the major strengths of case study research is theory building from it. There is established practice that case study research is specially used for theory building while quantitative research is considered appropriate for theory testing (Gummesson, 2007). Thus, though case study is used both for theory building and theory testing its use is more significantly recognized for its contributing role to theory building (Berg, 2007). Such views emphasize the role of case study research in theory building and in the meantime associate it with the qualitative research. There are mainly two approaches of theory building from the case study- one is theory development before case study research which was propounded by Yin and another is theory development from case study following the approach of grounded theory (Berg, 2007). This paper follows the latter approach as it is the practice of theory building in qualitative research.

Particularly, I follow the inductive theory building perspective of Locke (2007) as he argues that positivist perspective of theory building which is used in hard sciences does not fit for social sciences.

Though qualitative case study is considered highly useful research method in theory building, a foremost issue of the case study research is the existence of mythical belief that theory cannot be generated through it ( Simons, 2009; Widdowson, 2011). Undeniably, there are differing perspectives on the role of case study research in theory building. Thomas (2011) argues that case study research is not for drawing or building a theory as its focus is on particular and its findings are not generalizable. Stake (2006) also emphasizes on the role of case study research on particularization (Rule \& John, 2015). According to Flyvbjerg (2006) the understanding about the case study research is overly misguided through its conventional thought that treats the case study research in limited sense to be used only in the preliminary stage of any research but does not provide useful findings itself. Moreover, the misunderstandings about case study that it is not suitable for theory building are prominent (Flyvbjerg, 2006). Thus, "there are important and difficult problems still to be resolved concerning the role of case studies in producing valid theories" (Hammersley, Gomm\& Foster, 2000, p. 252).

Dooley (2002) argues that there is high possibility of developing new theory from case study research. Theory building from case studies is a research approach that develops theoretical concepts, proposals and mid range theory using single or multiple cases (Eisenhardt, 1989as cited in Eisenhardt \& Graebner, 2007). Gummesson (2014) justifies theory building from case study as he argues "By 
digging into complexity the core of a phenomenon can be found and valid and relevant theory based on real world data can be designed" (p. 12). As the theory building from case study is fully based on empirical research being free from the past theory or literature it is according to Eisenhardt (2002) "particularly well-suited to new research areas or research areas for which existing theory seems inadequate" (p. 32). Researchers intended to develop theory building from case study carefully select samples that are helpful in theory building. Such kind of sampling is known as theoretical sampling which does not select representative sample but select sample that provides illustrative picture of the cases useful to generate theories (Baskarada, 2014. In my understanding, selection of instrumental case helps researchers to illustrate the issue to the level of theoretical explanation.

Rule and John (2015) have given the process of theory building from case which is depicted in the diagram given below. Rule and John have called it inductive approach of theory building guided by the qualitative research where reasoning starts from a specific case and reach into a stage of theory and have stated that "The theory emerges from a systematic collection and analysis of data about the phenomenon" (p. 6).

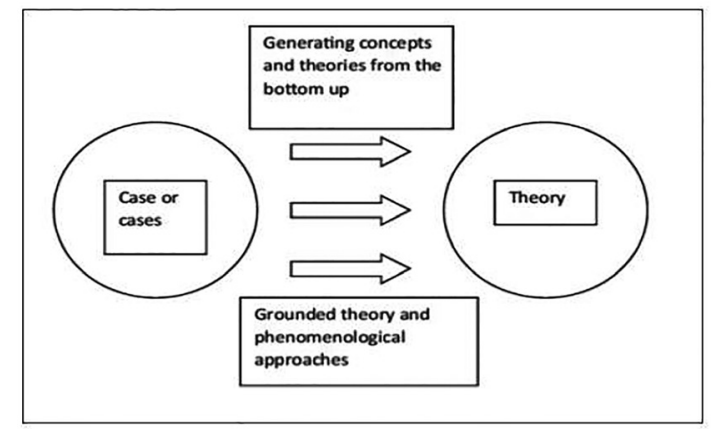

Figure: A theory building approach to case study (Adopted from Rule \& John, 2015, p. 7).

From case study research, according to Gummesson (2007) "we generate new and proved theory which continuously contributes to increased understanding. This is sometimes called analytical generalisation but it could just as well be called theory generation" (pp. 10-11). Eisenhardt (2002) argues that "building theory from case study research is most appropriate in the early stages of research on a topic or to provide freshness in perspective to an already researched topic" (p. 31).

From the discussions in the preceding sections it can be said that Stake's (1995) and Merriam's (2009) approaches of case study are more relevant from the perspective of theory building than of Yin's (2014) approach. Nonetheless, it does not mean that Yin's approach is not relevant. Particularly, his concept of analytic generalisation is useful in the process of theory building from case study. However, Yin's structured process does not support the notion of flexibility of qualitative research which is required in the process of theory building as theory emerges from the data in the research field which may not happen as per the prescribed structure. However, the case study designs that Yin explained are more inclined to qualitative research and are helpful to theory building except the relatively structured process that he has suggested.

There are some views that consider theory building from case study research in different ways. Though case study is popular for its strength in theory building, the process inherent with it is highly painstaking exercise as Eisenhardt (2002) points out it as a "strikingly iterative one" (p. 28) and Dooley (2002)comments it as "an arduous process" (p. 336). There is also view that theory cannot be generated from the case study research. However, Simons (2009) dismisses such view and argues that theory building from case study research is not an issue; it is rather what case study can do well. This all suggests that theory building from case study is not only a complex process but also has its fair share of challenges as well as misunderstandings. Now, in the remainder of this section I discuss the challenges and misunderstandings associated with the theory building from case study research.

Case study design, in spite of its increasing popularity, has certain challenges for its role in theory building. The reality is the absence of unambiguous concept of theory building from case study among the researchers. Some argue that methodological procedure on how to generate theory from cases are not clear (Dooley, 2002; Eisenhardt, 2002). Such comments reflect that there are challenges in understanding and applying the theory building from the case study research. However, various researchers have presented their strategies for theory building using case studies. In spite of efforts from some researchers in addressing the challenges of case study there are still some challenges and misunderstandings associated with the case study approach.

One of the challenges is maintaining parsimony of the theory developed from the case study. Parsimony, according to Patterson (1986), is an important feature of good theory which is difficult to maintain while building theory from case study research as it gathers huge data and becomes unable to show relationships properly (Dolley, 2002). To ensure parsimony of the theory generated from case study research Eisenhardt and Graebner (2007) suggest for multiple cases than single case since "single cases can enable the creation of more complicated theories than multiple cases" (p. 30). But my view here is that the issue of single case and multiple cases is not decisive. More important than this is objective of research and selection of appropriate case accordingly as the selection of case determines the nature of case study research. For example, one needs to be clear in the selection of caseintrinsic, instrumental or multiple cases.

Another challenge similar to the challenge of parsimony is to develop simple and workable theory from the case study since there is high chance, according to Eisenhardt (2002) that being excessively empirical in theory building can be unnecessarily complex due to high volume of data collected in the field. Eisenhardt has not discussed on how to address this problem of complexity. However, the possibility is that such complexity arises mainly when there are more cases in the case study. Since, the case study focus is one or few cases but for in-depth 
study of the case or cases it is essential to avoid many in order to make the theory manageable and presentable with optimal level of data collection as it is recommended that even a single case can generate useful theory to explain a particular context (Gummesson, 2014). To be specific in data collection and to avoid the lump of unmanageable data it becomes essential to focus research questions and carry out data collection accordingly to the relevance of research questions. It is argued that "Without a research focus, it is easy to become overwhelmed by the volume of data" (Eisenhardt, 2002, p. 10). The meaning of focus in case study research, in my understanding, is largely the selection of suitable case for its in-depth study.

However, selection of case itself in theory building from case study research is a common challenge as there is a view guided by positivist thinking that cases selected should represent the population (Eisenhardt \& Graebner, 2007). The argument for representative sampling applies for theory testing. But for the purpose of theory building theoretical sampling becomes suitable instead of representative sampling. In the theoretical sampling "cases are selected because they are particularly suitable for illuminating and extending relationships and logic among constructs" (Eisenhardt \& Graebner, 2007, p. 27). There are different views on appropriateness of single case or multiple cases for theory building from the case study research. As we see above, a single case can be enough (Siggelkow, 2007) while some researchers argue that multiple cases are more strong as they say multiple cases " create more robust theory because the propositions are more deeply grounded in varied empirical evidence" (Eisenhardt \& Graebner, 2007, p. 27). Thus, it can be said that the issue should not be single or multiple cases but selection of right case or cases as per the requirement of the research purpose and research questions. Therefore Stake (1994) opines that selection of cases is the fundamental feature of case study research.

One more challenge of case study research, according to Eisenhardt (2002), is generation of "narrow and idiosyncratic theory" as "Case study theory building is a bottom-up approach that the specifics of data produce the generalisations of theory" (p. 30). However, theory generation from case study should not be expected as grand or middle range theory rather as substantiate theory (Gummesson, 2007). Hence, it is not logical to consider theory building from case study as a narrow and idiosyncratic process. It is because "The crucial question is not whether the findings can be generalised to a wider universe but how well the researcher generates theory out of the findings" (Mitchell, 1983; as cited in Bryman, 2012, p. 57). This suggests as mentioned above to generate theory from the data following inductive reasoning process.

Flyvberg (2011) has discussed at length the misunderstandings about case study. Of the five misunderstandings that Flyvberg has identified some are similar to that I discussed above. But one misunderstanding as identified by Flyvberg is particularly important in relation to theory building from the case study which is "It is often difficult to summarize and develop general propositions and theories on the basis of specific case studies" (Flyvberg, 2011, p. 302). In counter of this argument of misunderstanding, drawing from various case study researches, Flyvberg ( 2011) argues that "despite the difficulty or undesirability in summarizing certain case studies, the case study as such can certainly contribute to the cumulative development of knowledge" (p. 313). Further, Flyvberg citing George and Bennett (2005, pp. 6-9) confirms that "case studies are especially well suited for theory development" (p. 306).

Another misunderstanding on theory building from case studies is that "the process is limited by investigators' preconceptions" (Eisenhardt, 2002, p. 29). But, Eisenhardt (2002) argues that this is only a myth since extreme cases in case studies are taken into consideration to find the "conflicting realities" (p. 29) that helps researcher to minimize biases. In addition, use of multiple cases helps researcher to overcome biases. Even in case of single case the data sources will be multiple and with the triangulation of data researchers can overcome the biases. Simons (2009) also points out that to see high subjectivity as a challenge of case study research is myth since subjectivity is inherent quality of any research and it should not be perceived as a weakness of the case study research itself.

From the discussions made above it appears that there are both challenges and misunderstandings about theory building from the case study research. The challenges are natural in the sense that most of the challenges are not only of case study but also apply to other qualitative research methods. But, specifically the foremost challenges of theory building from case study research are arisen due to the differences in philosophical assumptions of researchers and the selection of appropriate case. For example selection of appropriate case for theory building is one prominent challenge as many things depend upon it. There is also complexity about the use of single or multiple cases. But, there are more misunderstandings compared to challenges. The prevailing misunderstandings are mainly due to the differences of world view of researchers as positivist researchers hesitate to consider the findings of qualitative research as scientific research findings. According to Bryman (2012), the vital question is the quality of theory building from the case study research which depends upon how data and arguments relationships are established. Indeed, if case or cases are well selected, qualitative case study researches provide richer theoretical insights than large empirical research and sample survey (Flyvberg, 2011; Siggelow, 2007). Thus, various authors have supported the argument that case study research is appropriate for theory building particularly from the qualitative case study research and declined the doubts of positivist researchers that theory cannot be generated from case study.

\section{Conclusion}

This paper discusses the philosophical position of case study research as an essential ingredient to understand and practice it. Depending upon the nature of case whether 
it is simple or complex guides the selection of research paradigms. For the simple and directly measurable phenomenon quantitative research approach can be appropriate. But for the complex issue an in-depth study becomes essential which ask for the qualitative research approach. One of the important strengths of case study research is its ability to carry out in-depth study of a complex phenomenon. Hence, case study research is largely informed by qualitative research. Foremost strength of qualitative case study research is theory building from it. However, there are certain challenges and misunderstandings on the role of case study research in theory building. Some of the challenges for example are like maintaining parsimony of the theory developed, narrow and idiosyncratic theory, and dominance of researchers' preconceptions. These are such issues which can be addressed following appropriate strategies mainly by holding clear understanding of the philosophical position of the case study and selecting appropriate case as per the objective of research. It is, therefore, natural that like other research methods, the case study research has certain challenges; however, surprisingly there are more misunderstandings associated with it than the challenges. Further, most of the challenges and misunderstandings overlap causing the overall understanding of the case study research to be somewhat muddled for novice researchers. Most vital misunderstanding is that theory cannot be generated from the case study research. This and other similar misunderstandings, on the other hand, are arisen due to the differences in the researchers' perspectives particularly positivistic thinking of them rather than the shortcomings inherent in the qualitative case study research design.

\section{References}

Atieno, O. P. (2009). An analysis of the strengths and limitation of qualitative and quantitative research paradigms. Problems of Education in the 21 st Century, 13, 13-18.

Bartlett, L. \& Vavrus, F. (2017). Comparative Case Studies: An Innovative Approach. Nordic Journal of Comparative and International Education (NJCIE), 1(1), 5-17.

Baxter, P., \& Jack, S. (2008). Qualitative case study methodology: Study design and implementation for novice researchers. The Qualitative Report, 13(4), 544559.

Berg, B. L. (2007). Qualitative research methods for social sciences. Boston: Pearson.

Boblin, S.L., Ireland, S., Kirkpatrick, H., \& Robertson, K. (2013). Using Stake's Qualitative Case Study Approach to Explore Implementation of EvidenceBased Practice, Qualitative Health Research, XX(X), 1-9. DOI: $10.1177 / 1049732313502128$.

Brown, P. A. (2008). A review of the literature on case study research. Canadian Journal for New Scholars in Education, 1(1), 1-13.

Bryman, A. (2012). Social research methods (4th Edition).
New York: Oxford University Press.

Chadderton, C and Torrance, H. (2012). Case Study. In Somekh, B and Lewin, C (Eds.), Theory and methods in social research (pp. 53-68). New Delhi : SAGE.

Crowe, S., Cresswell, K., Robertson, A., Huby, G., Avery,A. \& Aziz Sheikh, A. The case study approach. BMC Medical Research Methodology, 11(100), 1-9.

Dooley, L. M. (2002). Case study research and theory building. Advances in Developing Human Resources, 4(3), 335-354.

Eisenhardt, K. M. (2002). Building theories from case study research. In Huberman, A. M. and Miles, M. B. (Eds.), The qualitative researcher companion (pp. 4-36). Thousand Oaks: Sage.

Eisenhardt, K. M. and Graebner, M. E. (2007). Theory building from cases: Opportunities and challenges. Academy of Management Journal, 50(2), 25-32.

Flyvbjerg, B. (2011). Case Study. In Norman K. Denzin and Yvonna S. Lincoln, (Eds.), The Sage Handbook of Qualitative Research (pp. 301-316). Thousand Oaks, CA: Sage.

George, A.L and Bennett, A. (2004). Case studies and theory development in the social sciences. London: MIT Press.

Gerring, J. (2007). Case study research: Principles and practices. Cambridge, New York: Cambridge University Press.

Gummesson, E. (2007). Case study research. In Gustavsson, Bengt (Ed.), The Principles of Knowledge Creation Methods. Cheltenham, UK: Edward Elgar.

Gummesson, E. (2014). Service research methodology: from case study research to case theory. RevistalberoAmericana de Estrategi, 13(4), 8-17.

Hammersley, M ,Gomm, R. \& Foster, P. (2000). Case study and theory. In Gomm, R., Hammersley, M. and Foster, P. (Eds.), Case study method (pp. 234-258). London: SAGE.

Harrison, H., Birks, M., Franklin, R. \& Mills, J. (2017). Case study research: Foundations and methodological orientations. Forum: Qualitative Social Research, 18(1), Art. 19, 34 paras. Retrieved from http://nbnresolving.de/urn:nbn:de:0114-fqs1701195

Jensen, J. L and Rodgers, R. (2001).Cumulating the intellectual gold of case study research. Public Administration Review, 61(2), 235-246.

Johansson, R. (2003). Key note speech at the international conference "Methodologies in Housing Research," Royal Institute of Technology in cooperation with the International Association of People-Environment Studies, Stockholm, September 22-24, 2003. Retrieved from http://www.psyking.net/htmlobj-3839/case_ study_methodology-_rolf_johansson_ver_2.pdf

Locke, E.A. (2007). The case for inductive theory building. Journal of Management, 33(6), 867-890.DOI: $10.1177 / 0149206307307636$

Lynham, S. A. (2002). The general method of theorybuilding research in applied disciplines. Advances in Developing Human Resources, 4(3), 221-241.

Merriam, S. B. (2009). Qualitative research: a guide to 
design and implementation. San Francisco: JosseyBass.

Mills, A. J., Eurepos, G., and Wiebe, E. (2010). Encyclopaedia of case study research (Eds.). London: Sage.

Rule, P. \& John, V. M. (2015). A necessary dialogue: Theory in case study research. International Journal of Qualitative Methods, 1(11). DOI: $10.1177 / 1609406915611575$.

Shoemaker, P. J., Tankard, J. M., \& Lasorsa, D. L, Jr. (2004). How to build social science theories. London: Sage.

Siggelkow, N. (2007). Persuasion with case studies. Academy of Management Journal, 50(1), 20-24.

Simons, H. (2009). Case study research in practice. London: SAGE.

Stake, R. E. (1994). Case studies. In Norman K. Denzin and Yvonna S. Lincoln (Eds.), Handbook of Qualitative Research (4th Edition) (pp. 236-247). Thousand Oaks, CA: Sage.

Stake, R. E. (1995).The art of case study research. London: Sage.

Stake, R. E. (2006). Multiple case study analysis. London: The Guilford Press.

Strauss, A., and Corbin, J. (1998).Basics of qualitative research: Techniques and procedures for developing grounded theory (2nd Edition). Thousand Oaks: SAGE.

Swedberg, R. (2012). Theorizing in sociology and social science: Turning to the context of discovery. Theory and Society, 41, 1-40.

Thomas, G. (2011). How to do your case study: a guide for students and researchers. London: SAGE.

Widdowson, MDJ. (2011). Case study research methodology. Retrieved from http://usir.salford. ac.uk/30763/

Yazan, B. (2015). Three approaches to case study methods in education: Yin, Merriam, and Stake. The Qualitative Report, 20 (2), 134-152.

Yin, R. K. (2014). Case study research: Design and methods (5th Edition). London: SAGE.

Bhatta, Thakur Prasad (ORCID: https://orcid.org/00000002-6431-2623) has been working as an evaluator and researcher in the field of development. He is affiliated with professional organization Community of EvaluatorsNepal and currently carry the responsibility as its General Secretary. He possess two master degrees in Sociology and Economics from Tribhuvan University, Nepal. At present, $\mathrm{He}$ is pursuing $\mathrm{PhD}$ from Kathmandu University, School of education. His areas of interest are qualitative research, development sociology, policy study, decentralization, planning and governance. He has participated in some international academic conferences and published research articles.

Email: thakurpbhatta@gmail.com 